\title{
Long-lived radionuclides
}

\section{Catherine Chauvel,}

Université de Paris, Institut de physique du globe de Paris, CNRS, F-75005 Paris, France chauvel@ipgp.fr

\section{Introduction}

Most chemical elements have several isotopes, but some of these isotopes are not stable because of an excess of nuclear energy. The consequence is that they decay into another isotope, often one of another element. The rate at which the decay occurs is quantified by the 'decay constant' $\lambda$, a parameter that expresses the probability of decay per unit of time. A more intuitive view of the decay process is the amount of time required for the decaying isotope to reduce to one half of its initial abundance. This is called the half-life and denoted by the symbol $t_{1 / 2}$ with:

\section{$\mathrm{t}_{1 / 2}=\ln (2) / \lambda \quad$ equation 1}

Many radioactive isotopes decay to produce a stable radiogenic isotope. The radioactive isotope is called the 'parent', and the radiogenic isotope produced by decay the 'daughter'. The combination of the two is the basis of most geochronological clocks used in Earth sciences. By measuring the ratio of 'parent' to 'daughter' and the ratio of the radiogenic 'daughter' isotope to a stable isotope of the same element that is not involved in a radioactive system, one can quantify the time it took to produce the quantity of 'daughter' isotopes observed in a rock or mineral:

$$
\left(\frac{D}{D^{\prime}}\right)_{t}=\left(\frac{D}{D^{\prime}}\right)_{0}+\left(\frac{P}{D^{\prime}}\right)_{t}\left(e^{\lambda t}-1\right) \quad \text { equation } 2
$$

with $\mathrm{D}$ the radiogenic 'daughter' isotope, $\mathrm{D}$ ' the stable isotope of the same element as $\mathrm{D}, \mathrm{P}$ the radioactive 'parent' isotope, $t$ the time since the rock or mineral first formed, and $\lambda$ the decay constant of the system.

Most radioactive isotopes decay quite rapidly, but some have very long half-lives, up to billions of years, and are commonly referred to as long-lived radionuclides. There may not be a specific definition of what long-lived means exactly, but the geochemical community usually uses this term to describe systems in which the half-life is expressed in billions of years. The following question could be raised: What unique insights into are provided by systems that decay so slowly? This might be counterintuitive, but the main advantage of long-lived radionuclides is that they decay over similar timescales as many geological processes.

To illustrate this, Figure 1 shows how four different radionuclides decay; two of them decay quickly (hafnium $182\left[{ }^{182} \mathrm{Hf}\right]$ and samarium $146\left[{ }^{146} \mathrm{Sm}\right]$ ), and two decay slowly (rubidium 87 $\left[{ }^{87} \mathrm{Rb}\right]$ and uranium $\left.238\left[{ }^{238} \mathrm{U}\right]\right)$. Over the Earth's lifetime, about half of ${ }^{238} \mathrm{U}$ has decayed into lead $206\left[{ }^{206} \mathrm{~Pb}\right.$ ], and about $10 \%$ of ${ }^{87} \mathrm{Rb}$ decayed into strontium $87\left[{ }^{87} \mathrm{Sr}\right.$ ]. In contrast, within the first $100 \mathrm{Ma}$ after the planet's accretion, nearly all ${ }^{182} \mathrm{Hf}$ decayed into tungsten $182\left[{ }^{182} \mathrm{~W}\right]$, and up to half of the Earth's ${ }^{146} \mathrm{Sm}$ decayed into neodymium $142\left[{ }^{142} \mathrm{Nd}\right]$. Thus, no radiogenic ${ }^{182} \mathrm{~W}$, and only limited ${ }^{142} \mathrm{Nd}$, have been produced since that time, meaning these radioactive systems $\left({ }^{182} \mathrm{Hf} \rightarrow{ }^{182} \mathrm{~W}\right.$ and $\left.{ }^{146} \mathrm{Sm} \rightarrow{ }^{142} \mathrm{Nd}\right)$ cannot be used to date any geological event that has occurred over the last $4.4 \mathrm{Ga}$. However, relics of differentiation at the very beginning of Earth 
history have be recorded by excesses or deficits in ${ }^{182} \mathrm{~W}$ or ${ }^{142} \mathrm{Nd}$. Such systems are called 'extinct' radioactive systems. In contrast, most ${ }^{87} \mathrm{Rb}$ and a large portion of ${ }^{238} \mathrm{U}$ are still presently decaying and generating radiogenic daughters, and these clocks can be used for geochronological purposes on samples with almost any age.
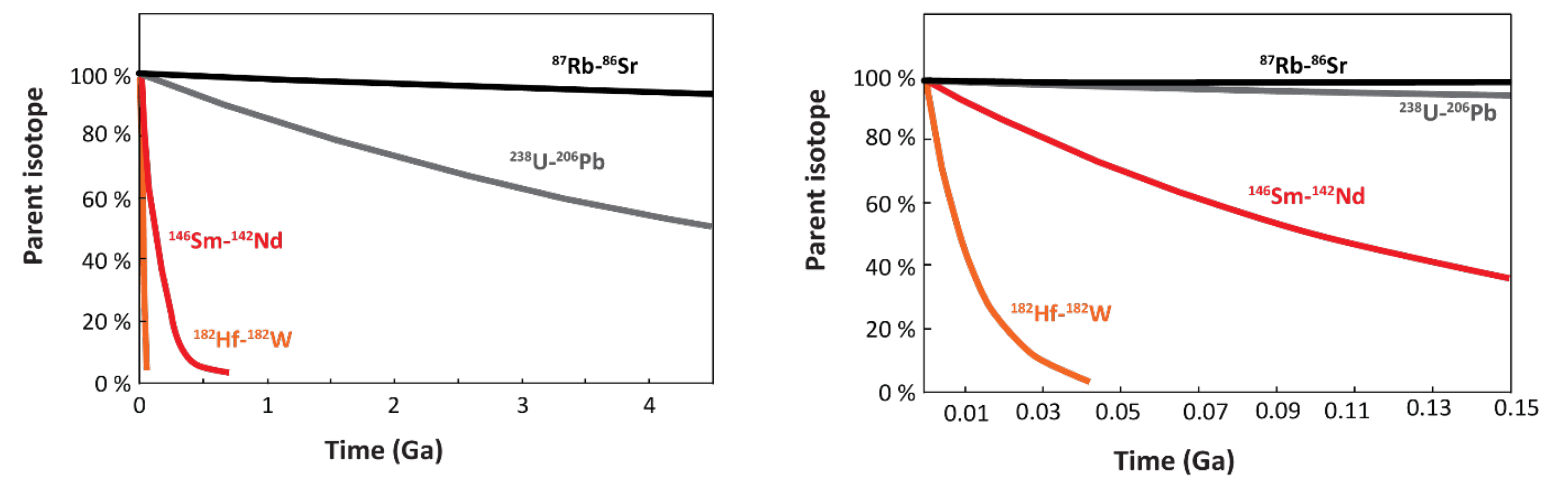

Figure 1: Decays of four parent isotopes with very different half-lives. The right panel corresponds to a blowup of the first $150 \mathrm{Ma}$ of the left panel.

There are six main long-lived radionuclides used in the Earth and planetary science communities. Below, I provide the main parameters for each parent-daughter pair and will present separately the most important geochronological geochemical applications.

\section{The main long-lived radionuclides}

\section{- Rubidium-strontium system}

Rubidium $(\mathrm{Rb})$ is an alkali metal with two isotopes $\left({ }^{85} \mathrm{Rb}\right.$ and $\left.{ }^{87} \mathrm{Rb}\right)$ that is present in trace quantities in rocks. Due to the similarities between the valence state $(1+)$ and ionic radius $(1.48$ $\AA$ ) of $\mathrm{Rb}^{+}$and those of $\mathrm{K}^{+}(1.33 \AA)$, Rb easily substitutes for $\mathrm{K}$ in mineral structures. Strontium $(\mathrm{Sr})$ is an alkaline earth element with four stable isotopes $\left({ }^{84} \mathrm{Sr},{ }^{86} \mathrm{Sr},{ }^{87} \mathrm{Sr}\right.$ and $\left.{ }^{88} \mathrm{Sr}\right)$. Like $\mathrm{Rb}$, $\mathrm{Sr}$ is a trace element and efficiently substitutes for $\mathrm{Ca}^{2+}$ in many geological phases due to their similar valence states and ionic radii. Rocks or minerals rich in $\mathrm{K}$, such as granite or clay, are thus usually rich in $\mathrm{Rb}$ while rocks rich in $\mathrm{Ca}$, such as carbonates, have elevated $\mathrm{Sr}$ concentrations. Notably, Rb-rich rocks are usually poor in $\mathrm{Sr}$ and vice-versa. As a consequence, the range of $\mathrm{Rb} / \mathrm{Sr}$ in geological materials can be extremely broad with values as low as 0.05 in basaltic rocks and as high as 2 in differentiated granites. The relatively high concentrations of $\mathrm{Rb}$ and $\mathrm{Sr}$ in geological materials, together with the large range of $\mathrm{Rb} / \mathrm{Sr}$ ratios, explains why the ${ }^{87} \mathrm{Rb}-{ }^{87} \mathrm{Sr}$ isotopic scheme has been used very early on to obtain the age of rocks. In this system, ${ }^{87} \mathrm{Rb}$ decays into ${ }^{87} \mathrm{Sr}$ with a half-life of $49.61 \mathrm{Ga}\left(\lambda=1.3972 * 10^{-}\right.$ $11 \mathrm{yrs}^{-1}$ ) which means that the isotopic system has very broad applications for large-scale planetary processes. The general equation for the ${ }^{87} \mathrm{Rb}-{ }^{87} \mathrm{Sr}$ system, derived from the fundamental structure of eq. 2 , is:

$\left(\frac{{ }^{87} S r}{{ }^{86} S r}\right)_{t}=\left(\frac{{ }^{87} S r}{{ }^{86} S r}\right)_{0}+\left(\frac{{ }^{87} R b}{{ }^{86} S r}\right)_{t}\left(e^{\lambda t}-1\right) \quad$ equation 3

\section{- Samarium-neodymium system}

Samarium (Sm) and neodymium (Nd) are both rare-earth elements (REE) and as such have very similar geochemical behaviours. As all REE, they are present in trace quantities in most 
geological materials. Most rocks and minerals contain on the order of ppm levels of REE, but few materials (such as phosphates) can be much richer in REE, with total REE contents at the percent level. Samarium has seven isotopes $\left({ }^{144} \mathrm{Sm},{ }^{147} \mathrm{Sm},{ }^{148} \mathrm{Sm},{ }^{149} \mathrm{Sm},{ }^{150} \mathrm{Sm},{ }^{152} \mathrm{Sm}\right.$ and ${ }^{154} \mathrm{Sm}$ ) plus two extinct isotopes $\left({ }^{146} \mathrm{Sm}\right.$ and $\left.{ }^{153} \mathrm{Sm}\right)$, one of which $\left({ }^{146} \mathrm{Sm}\right)$ is of interest to study the early evolution of the Earth (Figure 1). Neodymium also has seven isotopes $\left({ }^{142} \mathrm{Nd},{ }^{143} \mathrm{Nd}\right.$, ${ }^{144} \mathrm{Nd},{ }^{145} \mathrm{Nd},{ }^{146} \mathrm{Nd},{ }^{148} \mathrm{Nd}$ and ${ }^{150} \mathrm{Nd}$ ), all of which are stable, but two are produced by radioactive decay of an isotope of samarium. Specifically, ${ }^{142} \mathrm{Nd}$ was produced by ${ }^{146} \mathrm{Sm}$ before it was extinct, and ${ }^{143} \mathrm{Nd}$ continues to be produced by ${ }^{147} \mathrm{Sm}$. Because $\mathrm{Sm}$ and $\mathrm{Nd}$ are both REE and behave analogously during many planetary events (e.g., melting and crystallization processes), the $\mathrm{Sm} / \mathrm{Nd}$ ratio of geological materials is quite constant, with a total range limited between 0.15 and $0.4 .{ }^{147} \mathrm{Sm}$ decays into ${ }^{143} \mathrm{Nd}$ with a half-life of $106.25 \mathrm{Ga}\left(\lambda=6.524 * 10^{-12}\right.$ $\left.\mathrm{yrs}^{-1}\right)$, meaning that the isotopic system may be best applied to date rocks formed before the Phanerozoic, though chronological constraints applied to younger materials are not precluded. The general equation for the ${ }^{147} \mathrm{Sm}-{ }^{143} \mathrm{Nd}$ system is:

$\left(\frac{143 N d}{{ }^{144} N d}\right)_{t}=\left(\frac{{ }^{143} N d}{{ }^{144} N d}\right)_{0}+\left(\frac{{ }^{147} S m}{{ }^{144} N d}\right)_{t}\left(e^{\lambda t}-1\right)$ equation 4

Early in Earth's history, when ${ }^{146} \mathrm{Sm}$ was actively decaying into ${ }^{142} \mathrm{Nd}$ with a half-life of 103 $\operatorname{Ma}\left(\lambda^{\prime}=0.00673 * 10^{-6} \mathrm{yrs}^{-1}\right)$, the following equation applied:

$\left(\frac{142 N d}{{ }^{144} N d}\right)_{t}=\left(\frac{142 N d}{{ }^{144} N d}\right)_{0}+\left(\frac{146}{{ }^{144} N d}\right)_{t}\left(e^{\lambda \prime t}-1\right)$ equation 5

It should be noted that the half-life of ${ }^{146} \mathrm{Sm}$ is still debated (see Villa et al., 2020 for details).

\section{- Lutetium-hafnium system}

Lutetium $(\mathrm{Lu})$, as $\mathrm{Sm}$ and $\mathrm{Nd}$, is a REE present in trace quantities in most geological materials. Lutetium is the heaviest and the smallest of the REE, which makes it the least incompatible of all REE. It is present in ppm levels in most rocks because few minerals, such as garnet, can accommodate significant amounts of it. Lutetium has one stable isotope, ${ }^{175} \mathrm{Lu}$, and one radioactive isotope, ${ }^{176} \mathrm{Lu}$. Hafnium is a high-field strength element (HFSE) that substitutes easily for zirconium because they have the same valence $(+4)$ and almost identical ionic radii. As a consequence, hafnium is present in significant amounts in zircon $\left(\mathrm{ZrSiO}_{4}\right)$ and baddeleyite $\left(\mathrm{ZrO}_{2}\right)$. Hafnium has six isotopes $\left({ }^{174} \mathrm{Hf},{ }^{176} \mathrm{Hf},{ }^{177} \mathrm{Hf},{ }^{178} \mathrm{Hf},{ }^{179} \mathrm{Hf}\right.$ and $\left.{ }^{180} \mathrm{Hf}\right)$, one of which, ${ }^{176} \mathrm{Hf}$, is produced by radioactive decay of ${ }^{176} \mathrm{Lu}$. Even though $\mathrm{Lu}$ and $\mathrm{Hf}$ belong to different geochemical groups, they are both quite insoluble and their concentrations in most geological materials is not significantly affected by processes such as weathering and higher temperature alteration. The isotopic pair can therefore be considered as a robust system that is not easily affected by secondary processes. Even if Lu is a REE while Hf is an HFSE, their behaviors during rock-forming processes are quite similar and the $\mathrm{Lu} / \mathrm{Hf}$ ratio of most terrestrial rocks varies only between 0.05 and 0.30 . However, select minerals, such as garnet and biotite, can have very high ratios around $2 .{ }^{176} \mathrm{Lu}$ decays into ${ }^{176} \mathrm{Hf}$ with a half-life of $37.1 \mathrm{Ga}\left(\lambda=1.867 * 10^{-}\right.$ $\left.{ }^{11} \mathrm{yrs}^{-1}\right)$. The general equation for the lutetium-hafnium system is

$\left(\frac{176 H f}{{ }^{177} H f}\right)_{t}=\left(\frac{176 H f}{{ }^{177} H f}\right)_{0}+\left(\frac{176 L u}{{ }^{177} H f}\right)_{t}\left(e^{\lambda t}-1\right)$ equation 6

This isotopic system was rarely exploited prior to the advent of plasma-source mass spectrometers, because the ionization potential of hafnium is relatively high (i.e., $6.8 \mathrm{eV}$ ) and 
large quantities of analyte were necessary to obtain a precise isotopic analysis using thermal ionization mass spectrometers. More efficient ionization in plasma-source mass spectrometers has enabled the field of applications of ${ }^{176} \mathrm{Lu}^{176} \mathrm{Hf}$ system (as well as others) to drastically grow within the last 25 years, particularly since in-situ measurements using laser sources have been developed.

\section{- Uranium-thorium-lead system}

Uranium (U), thorium $(\mathrm{Th})$ and lead $(\mathrm{Pb})$ are three elements usually present as trace elements in most geological materials. However, few minerals (zircons and monazite, for example) can accommodate large amounts of $U$ and/or Th, making them good candidates for mineral geochronology. Uranium has two long-lived isotopes, ${ }^{238} \mathrm{U}\left(\mathrm{t}_{1 / 2}=4.468 \mathrm{Ga}, \lambda_{1}=1.55125^{*} 10^{-10}\right.$ $\left.\mathrm{yrs}^{-1}\right)$ and ${ }^{235} \mathrm{U}\left(\mathrm{t}_{1 / 2}=0.7038 \mathrm{Ga},\left(\lambda_{2}=9.8485^{*} 10^{-10} \mathrm{yrs}^{-1}\right)\right.$, and thorium has one, ${ }^{232} \mathrm{Th}\left(\mathrm{t}_{1 / 2}=\right.$ $\left.14.01 \mathrm{Ga}, \lambda_{3}=4.9475^{*} 10^{-11} \mathrm{yrs}^{-1}\right)$. All three of these radionuclides undergo a long chain of decay processes to ultimately produce three stable isotopes of lead, ${ }^{206} \mathrm{~Pb},{ }^{207} \mathrm{~Pb}$ and ${ }^{208} \mathrm{~Pb}$, respectively. The three independent decays are governed by the following equations:

$$
\begin{aligned}
& \left(\frac{{ }^{206} P b}{{ }^{204} P b}\right)_{t}=\left(\frac{{ }^{206} P b}{{ }^{204} P b}\right)_{0}+\left(\frac{{ }^{238} U}{{ }^{204} P b}\right)_{t}\left(e^{\lambda_{1} t}-1\right) \text { equation } 7 \\
& \left(\frac{{ }^{207} P b}{{ }^{204} P b}\right)_{t}=\left(\frac{{ }^{207} P b}{{ }^{204} P b}\right)_{0}+\left(\frac{{ }^{235} U}{{ }^{204} P b}\right)_{t}\left(e^{\lambda_{2} t}-1\right) \text { equation } 8 \\
& \left(\frac{{ }^{208} P b}{204}\right)_{t}=\left(\frac{{ }^{208} P b}{{ }^{204} P b}\right)_{0}+\left(\frac{{ }^{232} T h}{{ }^{204} P b}\right)_{t}\left(e^{\lambda_{3} t}-1\right) \text { equation 9 }
\end{aligned}
$$

The half-lives of ${ }^{235,238} \mathrm{U}$ and ${ }^{232} \mathrm{Th}$ are quite different but sufficiently long to allow the use of these isotopic system to study processes occurring between the formation of the Earth, $4.56 \mathrm{Ga}$ ago, and more recent times (few Ma). In principle, these three isotopic clocks should provide three independent age estimates, but in practice this often is not the case mainly because of mass loss of $\mathrm{U}, \mathrm{Pb}$ or intermediate daughters in the decay chain. However, the combination of the three isotopic systems is nonetheless very powerful both for geochronological purposes and for tracing long-term processes on Earth as will be described further on.

\section{- Potassium-argon system}

Potassium (K) is an alkali metal with three isotopes $\left({ }^{39} \mathrm{~K},{ }^{40} \mathrm{~K}\right.$ and $\left.{ }^{41} \mathrm{~K}\right)$, and one of the eight most abundant chemical elements in the continental crust. Potassium is also one of the major constituents of several common minerals (e.g., micas, feldspars and clay minerals). Argon (Ar) is a noble gas with three isotopes $\left({ }^{36} \mathrm{Ar},{ }^{38} \mathrm{Ar}\right.$ and $\left.{ }^{40} \mathrm{Ar}\right)$. Like all noble gases, argon has a dominant valence of 0 and does not easily enter any mineral structure. Consequently, it is essentially sequestered in the atmosphere of Earth. ${ }^{40} \mathrm{~K}$ undergoes branch decay to ${ }^{40} \mathrm{Ar}$ $(\approx 10.5 \%)$ and ${ }^{40} \mathrm{Ca}(\approx 89.5 \%)$ with a half-life of $12.04 \mathrm{Ga}$ for ${ }^{40} \mathrm{Ar}\left(\lambda_{\varepsilon}=5.755^{*} 10^{-11} \mathrm{yrs}^{-1}\right)$ and $1.394 \mathrm{Ga}$ for ${ }^{40} \mathrm{Ca}\left(\lambda_{\beta}=4.9737 * 10^{-10} \mathrm{yrs}^{-1}\right)$. The decay relationships are described by:

${ }^{40} \mathrm{Ar}^{*}+{ }^{40} \mathrm{Ca} a^{*}={ }^{40} \mathrm{~K}\left[e^{\lambda t}-1\right] \quad$ equation 10

with $\lambda=\lambda_{\varepsilon}+\lambda_{\beta}$ and where the superscript * indicates 'radiogenic'. It follows that: 
${ }^{40} A r_{t}={ }^{40} A r_{0}+\frac{\lambda_{\varepsilon}}{\lambda_{\varepsilon}+\lambda_{\beta}}{ }^{40} K_{t}\left[e^{\left(\lambda_{\varepsilon}+\lambda_{\beta}\right) t}-1\right]$ equation 11

where the subscripts $t$ and 0 indicate total and initial.

The K-Ar system is essentially used for geochronological purposes and is particularly powerful to date igneous and metamorphic events in the continental crust. It is also widely used to date eruption ages of volcanoes, and has been used to constrain the age of Martian mudstone in situ with the payload onboard the Curiosity rover (Farley et al., 2014).

\section{- Rhenium-osmium system}

Rhenium (Re) and osmium (Os) are both members of the sixth period of the periodic table of elements. While Re has chemical properties similar to molybdenum (Mo), Os is one of the six platinum-group elements (PGEs). Both Re and Os are strongly siderophile and present in minute quantities in terrestrial rocks; their concentrations are extremely low in igneous rocks (at ppb levels) in contrast to the elevated contents observed in many meteorites (e.g., up to ppm in iron meteorites). Despite the limited content of Re and Os found in terrestrial rocks, the $\mathrm{Re} /$ Os ratio can vary between low values $(\approx 0.1)$ in ultramafic rocks and high values $(\approx 10)$ in continental crust. Rhenium has two stable isotopes $\left({ }^{185} \mathrm{Re}\right.$ and $\left.{ }^{187} \mathrm{Re}\right)$, one of which, ${ }^{187} \mathrm{Re}$, decays into ${ }^{187} \mathrm{Os}$ with a half-life of $41.6 \mathrm{Ga}\left(\lambda=1.666^{*} 10^{-11} \mathrm{yrs}^{-1}\right)$. Osmium has seven isotopes $\left({ }^{184} \mathrm{Os},{ }^{186} \mathrm{Os},{ }^{187} \mathrm{Os},{ }^{188} \mathrm{Os},{ }^{189} \mathrm{Os},{ }^{190} \mathrm{Os}\right.$ and $\left.{ }^{192} \mathrm{Os}\right)$. The general equation is:

$\left(\frac{187 O s}{{ }^{188} O S}\right)_{t}=\left(\frac{187 O s}{{ }^{188} O s}\right)_{0}+\left(\frac{187 R e}{{ }^{188} O s}\right)_{t}\left(e^{\lambda t}-1\right) \quad$ equation 12

The Re-Os system is used for both geochronological purposes and geochemical tracing of source composition. It proves particularly successful for dating meteorites and Re-rich mineral phases, but the analytical challenges due to the low abundances contained within in terrestrial materials prevent the system from being more widely used.

Table 1: Summary of parameters for the main long-lived radionuclide systems

\begin{tabular}{|c|c|c|c|c|c|}
\hline Isotopic system & $\begin{array}{c}\text { Radioactive } \\
\text { parent }\end{array}$ & $\begin{array}{c}\text { Radiogenic } \\
\text { daughter }\end{array}$ & $\begin{array}{c}\text { Half-life } \\
\text { (Ga=109 years) }\end{array}$ & Decay constant & Reference \\
\hline $\mathrm{Rb}-\mathrm{Sr}$ & ${ }^{87} \mathrm{Rb}$ & ${ }^{86} \mathrm{Sr}$ & $49.61 \mathrm{Ga}$ & $1.3972 * 10^{-11}$ & Villa et al., 2015 \\
\hline Sm-Nd & ${ }^{147} \mathrm{Sm}$ & ${ }^{143} \mathrm{Nd}$ & $106.25 \mathrm{Ga}$ & $6.524 * 10^{-12}$ & Villa et al., 2020 \\
\hline Lu-Hf & ${ }^{176} \mathrm{Lu}$ & ${ }^{176} \mathrm{Hf}$ & $37.1 \mathrm{Ga}$ & $1.867 * 10^{-11}$ & Söderlund et al. 2004 \\
\hline \multirow{3}{*}{ U-Th-Pb } & $238 \mathrm{U}$ & ${ }^{206} \mathrm{~Pb}$ & $4.468 \mathrm{Ga}$ & $1.55125 * 10^{-10}$ & \multirow{2}{*}{ Jaffey et al., 1971} \\
\hline & ${ }^{235} \mathrm{U}$ & ${ }^{207} \mathrm{~Pb}$ & $0 . .7038 \mathrm{Ga}$ & $9.8485^{*} 10^{-10}$ & \\
\hline & ${ }^{232} \mathrm{Th}$ & ${ }^{208} \mathrm{~Pb}$ & $14.01 \mathrm{Ga}$ & $4.9475^{*} 10^{-11}$ & LeRoux \& Glendenin, 1963 \\
\hline $\mathrm{Re}-\mathrm{Os}$ & ${ }^{187} \operatorname{Re}$ & ${ }^{187} \mathrm{Os}$ & $41.6 \mathrm{Ga}$ & $1.666 * 10^{-11}$ & Smoliar et al. 1996 \\
\hline \multirow{3}{*}{$\mathrm{K}-\mathrm{Ar}-\mathrm{Ca}$} & ${ }^{40} \mathrm{~K}$ & ${ }^{40} \mathrm{Ar}$ & $12.04 \mathrm{Ga}$ & $5.755^{*} 10^{-11}$ & \multirow{3}{*}{ Renne et al., 2010} \\
\hline & ${ }^{40} \mathrm{~K}$ & ${ }^{40} \mathrm{Ca}$ & $1.394 \mathrm{Ga}$ & $4.9737^{*} 10^{-10}$ & \\
\hline & ${ }^{40} \mathrm{~K}$ & total & $1.249 \mathrm{Ga}$ & $5.5492 * 10^{-10}$ & \\
\hline
\end{tabular}

\section{Geochronology}

Long-lived radionuclides have been used for over 50 years to date geological and planetary materials. Short-lived radionuclides, such as the ${ }^{14} \mathrm{C}\left(\mathrm{t}_{1 / 2}=5730 \mathrm{a}\right)$ and ${ }^{10} \mathrm{Be}\left(\mathrm{t}_{1 / 2}=1.51 \mathrm{Ma}\right)$, are commonly used to date recent events (generally less than $1 \mathrm{Ma}$ ) but cannot be exercised to 
date events occurring at most geological time scales. For those time scales, the long-lived radionuclides are ideal tools. Two main types of applications are most common: (a) techniques in which the parent to daughter ratio is extremely high, in which case the amount of daughter isotope at the time of formation can be effectively neglected (e.g., the case for K-Ar and zircon $\mathrm{U} / \mathrm{Pb}$ methods); and, (b) techniques in which the amount of daughter isotope at time of formation cannot be neglected (all the isotopic systems using what is called the isochron technique).

\section{- the high parent-daughter ratio systems}

\section{- a- the potassium-argon technique}

While Ar is a rather common component of the Earth's atmosphere (about 1\%), it is present in extremely small amounts in rocks. As a consequence, virtually all the Ar present in K-rich materials comes from the decay of ${ }^{40} \mathrm{~K}$, defining the $\mathrm{K}$-Ar system as an ideal tool to date a large range of materials, especially K-rich minerals such as biotite, muscovite or hornblende. The age obtained using equation 9 is called a 'blocking temperature', i.e. the temperature below which the Ar is retained in the mineral. This corresponds to a minimum age for minerals that cooled down slowly. The disadvantage of the K-Ar method is that the two elements have very different geochemical behaviours, with one fitting in mineral structures but also being easily mobilized by fluid phases, and the other being an inert gas. This discrepancy, together with the difficulty of obtaining good errors on the absolute amounts of both $\mathrm{K}$ and Ar, introduces additional errors when calculating ages using equation 9. A variant was therefore developed and is now widely used by geochronologists, the so-called ${ }^{40} \mathrm{Ar} /{ }^{39} \mathrm{Ar}$ method. This variant uses the irradiation of samples by neutrons in a nuclear reactor to partially convert the sample's ${ }^{39} \mathrm{~K}$ content into ${ }^{39} \mathrm{Ar}\left(\mathrm{T}_{1 / 2}=269\right.$ years). The ratio of ${ }^{40} \mathrm{Ar}$ to ${ }^{39} \mathrm{Ar}$ can then be measured accurately during step heating, which releases noble gases from geological materials. The resulting spectrum of dates provides information about the cooling age of the samples, and the potential presence of excess argon when the mineral formed.

\section{- $b$ - the uranium-lead technique on zircons}

The most robust technique to obtain reliable ages on rocks that contain zircon is the U-Pb technique. This method was developed drastically with the advent of in-situ measurements by secondary ion mass spectrometry (SIMS), and is now widely used in the geosciences. Prior to the existence of SIMS instruments, zircons had to be isolated and chemically treated in clean laboratory environments to extract $\mathrm{Pb}$ (including its radiogenic isotopes) from their lattices. The U-Pb scheme is extremely powerful because the two isotopes of $\mathrm{U}$, each with distinct halflives, decay into two different isotopes of $\mathrm{Pb}$. Uranium readily substitutes for $\mathrm{Zr}^{4+}$ in the zircon structure, but $\mathrm{Pb}$ does not, resulting in high initial $\mathrm{U} / \mathrm{Pb}$. In addition, because zircons are extremely robust minerals (samples as old as $4.4 \mathrm{Ga}$ have been preserved in the rock record), they are resistant to secondary processes, and thus they often record and successfully maintain their crystallisation age. The classical technique to obtain the U-Pb age of zircons centers on the combination of the two U-based isotopic clocks into a single graph called a 'concordia' diagram (see Figure 2), which plots the evolution of the two daughter/parent ratios through time. In the absence of significant initial radiogenic lead, equations $7 \& 8$ become:

$$
\begin{array}{ll}
\left(\frac{{ }^{206} P b}{{ }^{238} U}\right)_{t}=\left(e^{\lambda_{1} t}-1\right) & \text { equation } 13 \\
\left(\frac{{ }^{207} P b}{{ }^{235} U}\right)_{t}=\left(e^{\lambda_{2} t}-1\right) & \text { equation } 14
\end{array}
$$




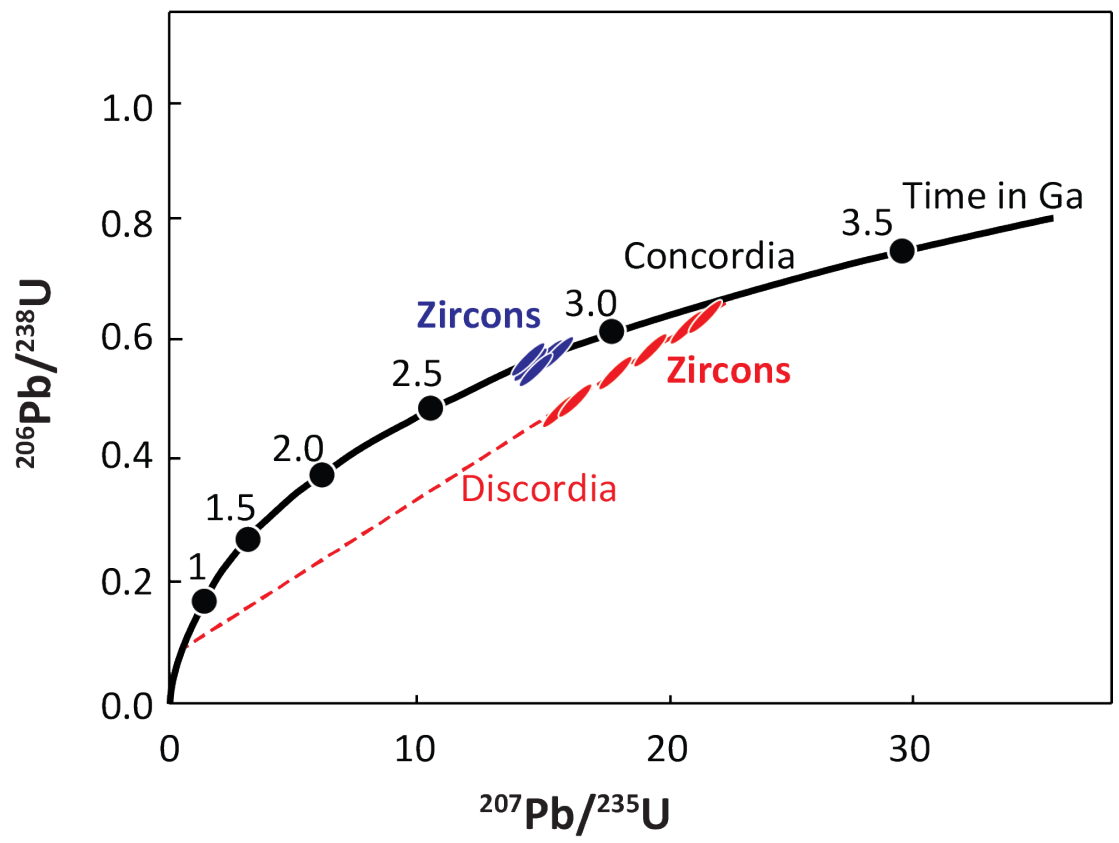

Figure 2: Concordia diagram showing how the ratios of the two daughter/parent isotopes of $\mathrm{Pb}$ and $\mathrm{U}$ vary through time. Because of the difference in decay constants, the evolution path over time follows a curve and not a straight line. Any material with a high $\mathrm{U} / \mathrm{Pb}$ ratio (i.e., zircon) that has not been disturbed since formation falls on the concordia curve, while zircons that have been partly reset after crystallisation, for example by a metamorphic event, fall on a line called a discordia.

\section{- the isochron technique}

In most isotopic systems, the amount of the radiogenic daughter isotope present in samples before the start of the isotopic clock cannot be neglected, and the age of the material cannot be calculated by just quantifying the amount of daughter isotope, as was the case with the previously described geochronological tools (e.g., K-Ar and U-Pb in zircon). However, there is another method that enables radiometric dating of materials called the isochron technique. Figure 3a shows how the isotopic compositions of several samples (e.g., rocks or minerals), formed at the same time from the same source, evolve over time due to their different parent/daughter ratios. At the time of formation, all samples have the same isotopic composition of the daughter element but different parent/daughter ratios, defining an horizontal line. With time, samples with higher parent/daughter ratios generate more radiogenic daughters over a given time interval, resulting in isotopic compositions more enriched in the radiogenic daughter. The slope of the line defined by the various rocks enables the age of the sample suite to be determined, and the intercept describes the initial ratio of the suite of rocks at time of emplacement.
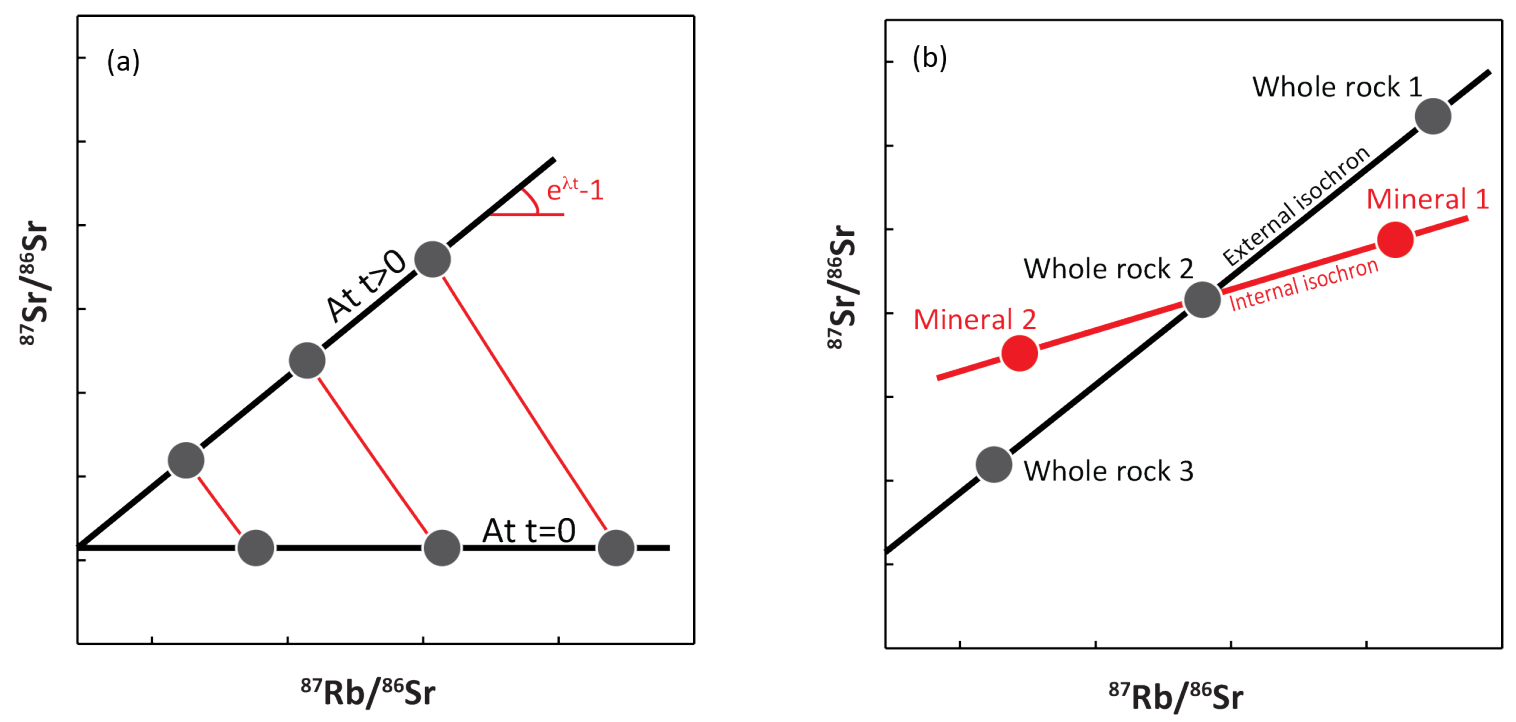
Figure 3: Isochron diagram. Panel a shows how the ${ }^{87} \mathrm{Sr} /{ }^{86} \mathrm{Sr}$ ratio of samples evolve through time according to their ${ }^{87} \mathrm{Rb} /{ }^{86} \mathrm{Sr}$ ratio. The intercept provides the initial ${ }^{87} \mathrm{Sr} /{ }^{86} \mathrm{Sr}$ of the rock series at the time of formation. Panel b shows how an external isochron corresponding to the age of emplacement of the rock series can be defined by a suite of whole rocks, while minerals derived from whole rock 2 define an internal isochron whose age corresponds to the crystallisation of the newly formed minerals, for example during metamorphism.

The technique is extremely powerful and has been used for decades to date all sorts of materials. It has been used to constrain the emplacement of basaltic lavas or the crystallisation of granites, but it has also been used to date metamorphic events. The first isotopic clock to be used was the ${ }^{87} \mathrm{Rb}-{ }^{86} \mathrm{Sr}$ system in the 1950 's, which was applied to date high-Rb materials, particularly granites. However, the fluid solubility of $\mathrm{Rb}$ and $\mathrm{Sr}$ promote mobilization during alteration and metamorphism; thus, the method often failed and no isochron could be obtained. This limited the application of the ${ }^{87} \mathrm{Rb}-{ }^{86} \mathrm{Sr}$ system for age determinations of old rock suites, such as the Archean crust.

In the 1970 's, the use of the ${ }^{147} \mathrm{Sm}-{ }^{143} \mathrm{Nd}$ system developed drastically and it was mainly used to derive ages for mafic and ultramafic rocks, materials very difficult to date using the ${ }^{87} \mathrm{Rb}$ ${ }^{86} \mathrm{Sr}$ system given the lack of high $\mathrm{Rb} / \mathrm{Sr}$ ratios. Mafic and ultramafic rocks usually display a range of $\mathrm{Sm} / \mathrm{Nd}$ ratios that is sufficiently large to obtain precise isochron ages of cogenetic lavas. The ${ }^{147} \mathrm{Sm}^{-143} \mathrm{Nd}$ system also has the advantage that the parent and daughter elements belong to the REE group, a cluster of elements that behave systematically (and thus predictably) during mantle melting, are insoluble in many fluids, and display limited mobility during alteration and metamorphism. This behaviour makes the ${ }^{147} \mathrm{Sm}_{-}{ }^{143} \mathrm{Nd}$ system a robust geochronological tool for constraining the ages of old samples, such as the Archean rocks. The ${ }^{176} \mathrm{Lu}-{ }^{176} \mathrm{Hf}$ system is similarly robust because both elements are also quite resistant to secondary processes, but because Lu is a REE and Hf a HFSE, their partitioning behaviours during silicate differentiation are significantly different. In some cases, the isotopic system does not remain closed and the preservation of an isochron is compromised. Nevertheless, the method proves very successful to date igneous and metamorphic rocks of Precambrian ages. It is particularly suited to date metamorphic events during which garnet crystallises.

\section{- the common-lead technique}

As described above, the U-Pb system is commonly used to date zircons but the isotopic clock can also be used to determine the age of various types of rocks using what is called the common-lead method. This method takes advantage of the fact that two isotopes of $U$ decay to two isotopes of $\mathrm{Pb}$. The growth of the two daughter isotopes is linked to their decay constants, and they are necessarily coupled. It can be summarized by the following equation that combines equations $7 \& 8$, and assumes a constant value of present-day ${ }^{238} \mathrm{U} /{ }^{235} \mathrm{U}$ at 137.88 :

$\frac{\left({ }^{207} P b /{ }^{204} P b\right)_{t}-\left({ }^{207} P b /{ }^{204} P b\right)_{0}}{\left({ }^{206} P b /{ }^{204} P b\right)_{t}-\left({ }^{206} P b /{ }^{204} P b\right)_{0}}=\frac{1}{137.88}\left(\frac{\left(e^{\lambda_{2} t}-1\right)}{\left(e^{\lambda_{1} t}-1\right)}\right) \quad$ equation 15

Figure 4 shows how an age can be calculated using the slope of the line defined by the sample set. In this historical example published by C. Patterson in 1956, the author determined the age of three stony and two iron meteorites $(\mathrm{T}=4.55 \pm 0.07 \mathrm{Ga})$ and demonstrated that the Earth had the same age since the modern terrestrial sediment fell on the same isochron. The same technique has since been applied to all sorts of old rock suites and proven particularly powerful to date Archean komatiites and basalts. 


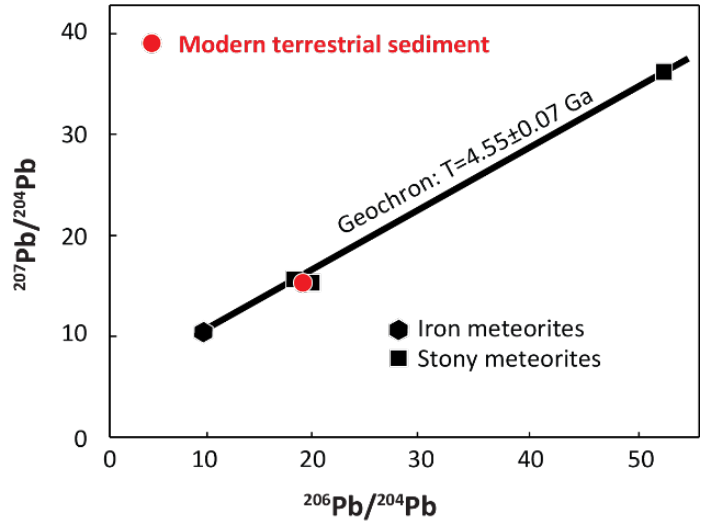

Figure 4: Lead isochron for meteorites published in 1956 by Patterson. The meteorites having very different $\mathrm{U} / \mathrm{Pb}$ ratios define an isochron giving the age of their formation. Patterson noticed that the single terrestrial sample that he measured falls on the same line and concluded that the Earth had the same age as the meteorites. Since 1956, the overall story has been refined but the main points are still valid to this day.

\section{Isotope geochemistry}

Since the early stages of accretion, the Earth has differentiated and new continental crust has been created. Formation of a sialic crust had a significant impact on the residual mantle because the processes involved during its extraction effectively fractionated the various parent-daughter systems described above. These isotopic systems were (and continue to be) modified in a systematic way due to the overall enrichment of incompatible trace elements (i.e., those that prefer the liquid phase over the solid) in the melt during magma formation and fractional crystallization. Consequently, continental crust is enriched in $\mathrm{K}, \mathrm{Rb}, \mathrm{U}$, Th and Re relative to the daughter products of their respective decay schemes. In contrast, the continental crust has lower $\mathrm{Sm} / \mathrm{Nd}$ and $\mathrm{Lu} / \mathrm{Hf}$ ratios than both the residual mantle and the bulk silicate Earth. As a consequence, crustal material evolves through time towards radiogenic $\mathrm{Ar}, \mathrm{Sr}, \mathrm{Pb}$ and $\mathrm{Os}$ values and unradiogenic $\mathrm{Nd}$ and $\mathrm{Hf}$ ratios. In contrast, the residual mantle evolves towards unradiogenic $\mathrm{Ar}, \mathrm{Sr}, \mathrm{Pb}$ and $\mathrm{Os}$ values and radiogenic $\mathrm{Nd}$ and $\mathrm{Hf}$ ratios. Such chemical signatures are extremely precious to trace the origin of rocks.
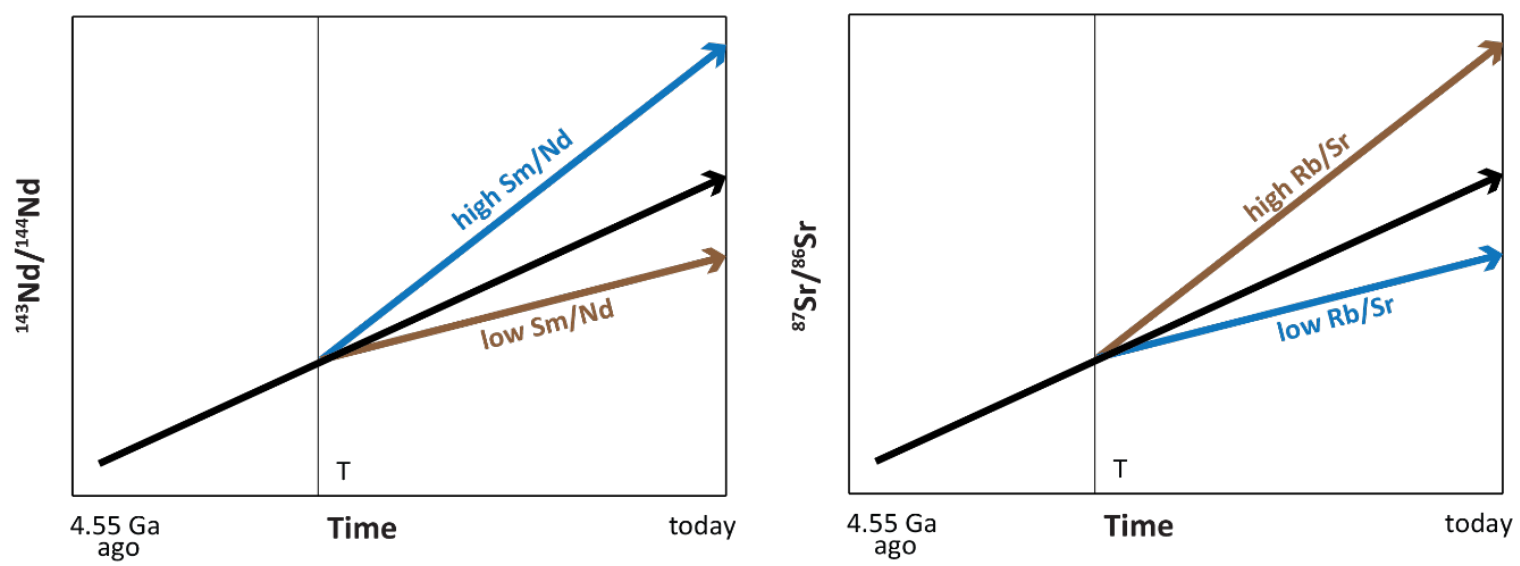

Figure 5: Sketch of the evolution over time of the isotopic ratios of $\mathrm{Nd}$ and $\mathrm{Sr}$ as a function of parent-daughter ratios. The black lines represent the evolution of bulk silicate earth (BSE), the brown lines continental crust and the blue lines residual mantle.

Figure 5 shows how fractionation of the parent/daughter ratio modifies the isotopic composition of the daughter element provided that enough time went past since the fractionation event. Old continental crust with its high $\mathrm{Rb} / \mathrm{Sr}$ ratio and low $\mathrm{Sm} / \mathrm{Nd}$ ratio evolves to high ${ }^{87} \mathrm{Sr} /{ }^{86} \mathrm{Sr}$ and low ${ }^{143} \mathrm{Nd} /{ }^{144} \mathrm{Nd}$ while the complementary depleted mantle evolves to low ${ }^{87} \mathrm{Sr} /{ }^{86} \mathrm{Sr}$ and high ${ }^{143} \mathrm{Nd} /{ }^{144} \mathrm{Nd}$. The origin of a geological material can therefore be traced by measuring its isotopic composition. 
Radiogenic isotope signatures are widely used in mantle geochemistry to understand the longterm evolution and the origin of sources of volcanic rocks. Perhaps the most important insights arise from the combined use of $\mathrm{Sr}$ and $\mathrm{Nd}$ isotopes, which together reveal multiple distinct mantle sources or domains defined by resolvable isotopic heterogeneities. As shown in Figure 6 , the upper mantle source of mid-ocean ridge basalts (MORB), characterized by high ${ }^{143} \mathrm{Nd} /{ }^{144} \mathrm{Nd}$ and low ${ }^{87} \mathrm{Sr} /{ }^{86} \mathrm{Sr}$, is relatively uniform and must have been depleted in incompatible elements by a major differentiation event long ago to reach such distinctive values. It is generally accepted that the depletion observed in the depleted MORB mantle (or DMM) is due primarily to the formation and isolation of continental crust over Earth history ( Hofmann, 1988).

Ocean island basalts $(\mathrm{OIB})$ in contrast define large isotopic ranges for $\mathrm{Sr}, \mathrm{Nd}$ and $\mathrm{Pb}$ (see Figure 6). They vary between four end-members (HIMU, EM 1, EM 2 and DMM) (Zindler and Hart, 1986). EM1 and EM2 stand for Enriched Mantle 1 and Enriched Mantle 2; it is generally agreed that the most radiogenic $\mathrm{Sr}$ and unradiogenic $\mathrm{Nd}$ resemble values characteristic of continental crust, suggesting that old crustal material has been recycled into the EM 1 and EM2 mantle end-members. HIMU stands for High- $\mu$ (high ${ }^{238} \mathrm{U} /{ }^{204} \mathrm{~Pb}$ ) and corresponds to the few intraplate volcanic centers characterized by extremely radiogenic $\mathrm{Pb}$ isotopic compositions. The origin of the HIMU end-member is thought to be recycled oceanic crust. While most intermediate OIB compositions can be explain by mixing of these four end-members, it has also been suggested that a fifth end-member called FOZO (Hart et al., 1992) or C occurs . In isotopic spaces, it falls at an intermediate position where most isotopic arrays converge.
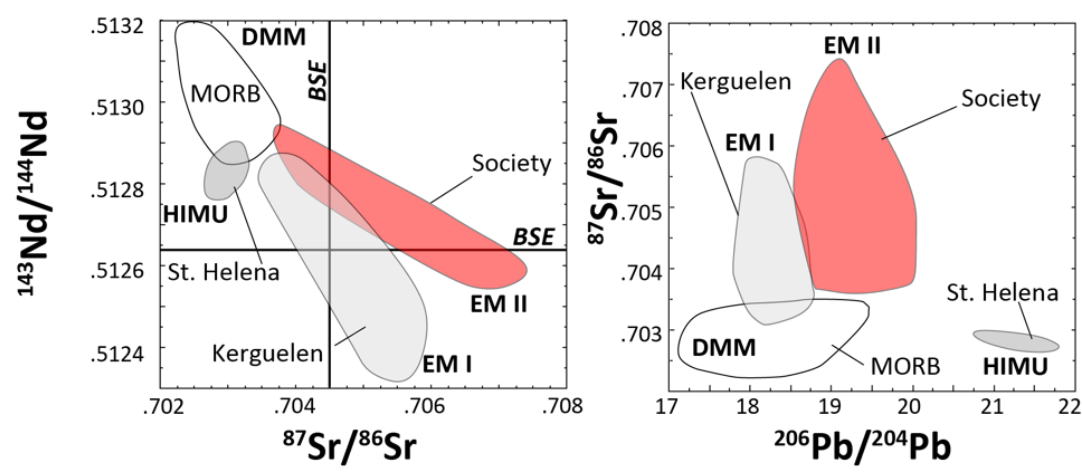

Figure 6: $\mathrm{Sr}$ vs $\mathrm{Nd}$ isotopic diagram showing fields for MORB and OIB. The directionality of the observed trends implicate multiple source components, or end-members, defined by distinct isotopic identities. The two lines correspond to the isotopic ratios of present-day bulk silicate Earth (BSE).

When studying continental crust, its formation and its evolution through geological times, radiogenic isotopes are also extremely useful. They are mainly used to characterize the proportion of new incoming material sourced from the mantle, and old crustal material reprocessed to form rejuvenated crust. The clearest example is the use of Hf isotopes measured on zircons. 


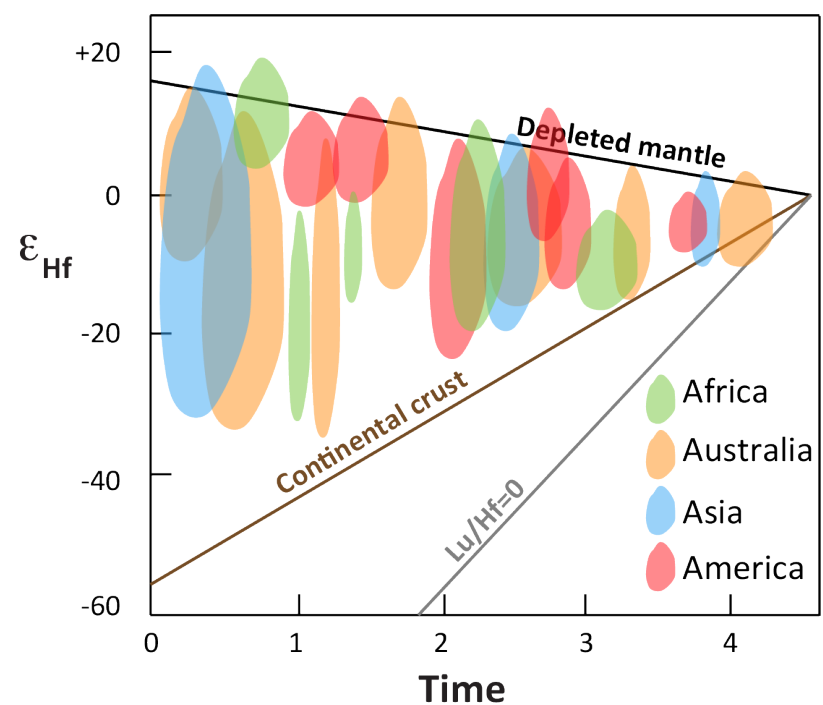

Figure 7: Hf isotopic composition of detrital zircons from all over the world plotted as a function of their $\mathrm{U}-\mathrm{Pb}$ age. $\varepsilon_{\mathrm{Hf}}$ measures the deviation of the ${ }^{176} \mathrm{H} /{ }^{177} \mathrm{Hf}$ ratio relative to the reference reservoir CHUR (chondritic uniform reservoir). Simplified from Belousova et al. (2010).

As an example, Figure 7 plots Hf isotopic data representing detrital zircons with ages ranging from over $4 \mathrm{Ga}$ to present-day. Zircons crystallizing from material coming directly from the mantle have elevated $\varepsilon_{\mathrm{Hf}}$ values, while zircons crystallizing from older crustal material have low $\varepsilon_{\mathrm{Hf}}$ values. All data falling in between suggest that the source of the crustal material consists in a mixture of newly formed crust and older recycled crust.

In summary, long-lived radionuclides contribute to major advances in our understanding of the Earth. They provide the most reliable ages and they put strong constraints on the long-term evolution of solid Earth.

References:

Belousova, E.A. et al., 2010. The growth of the continental crust: Constraints from zircon Hfisotope data. Lithos, 119(3-4): 457-466.

Farley, K.A. et al., 2014. In Situ Radiometric and Exposure Age Dating of the Martian Surface. Science, 343(6169): 1247166.

Hart, S.R., Hauri, E.H., Oschmann, L.A., Whitehead, J.A., 1992. Mantle Plumes and Entrainment: Isotopic Evidence. Science, 256(5056): 517-520.

Hofmann, A.W., 1988. Chemical differentiation of the Earth: the relationship between mantle, continental crust and oceanic crust. Earth Planet. Sci. Lett., 90: 297-314.

Jaffey, A.H., Flynn, K.F., Glendenin, L.E., Bentley, W.C., Essling, A.M., 1971. Precision Measurement of Half-Lives and Specific Activities of ${ }^{235} U$ and ${ }^{238} U$. Physical Review C, 4(5): 1889-1906.

Le Roux, L.J., Glendenin, L.E., 1963. Half-life of 232 Th. Proc. Natl. Meet. onNuclear Energy, Pretoria (1963), pp. 83-94 
Renne, P.R., Mundil, R., Balco, G., Min, K., Ludwig, K.R., 2010. Joint determination of 40K decay constants and $40 \mathrm{Ar} * / 40 \mathrm{~K}$ for the Fish Canyon sanidine standard, and improved accuracy for 40Ar/39Ar geochronology. Geochimica et Cosmochimica Acta, 74(18): 5349-5367.

Smoliar, M.I., Walker, R.J., Morgan, J.W., 1996. Re-Os Ages of Group IIA, IIIA, IVA, and IVB Iron Meteorites. Science, 271(5252): 1099-1102.

Soderlund, U., Patchett, P.J., Vervoort, J.D., Isachsen, C.E., 2004. The 176Lu decay constant determined by Lu-Hf and U-Pb isotope systematics of Precambrian mafic intrusions. Earth and Planetary Science Letters, 219(3-4): 311.

Villa, I.M., De Bièvre, P., Holden, N.E., Renne, P.R., 2015. IUPAC-IUGS recommendation on the half life of 87Rb. Geochimica et Cosmochimica Acta, 164: 382-385.

Villa, I.M. et al., 2020. IUPAC-IUGS recommendation on the half-lives of $147 \mathrm{Sm}$ and $146 \mathrm{Sm}$. Geochimica et Cosmochimica Acta, 285: 70-77.

Zindler, A., Hart, S., 1986. Chemical geodynamics. Ann. Rev. Earth Planet. Sci., 14: 493-571. 